\title{
Mechanical Properties, Surface Structure, and Morphology of Carbon Fibers Pre-heated for Liquid Aluminum Infiltration
}

\author{
Franziska S. Kachold, Rafal Kozera, Robert F. Singer, and Anna Boczkowska
}

\author{
(Submitted January 7, 2016; in revised form February 29, 2016; published online March 15, 2016)
}

\begin{abstract}
To efficiently produce carbon fiber-reinforced aluminum on a large scale, we developed a special highpressure die casting process. Pre-heating of the fibers is crucial for successful infiltration. In this paper, the influence of heating carried out in industrial conditions on the mechanical properties of the fibers was investigated. Therefore, polyacrylonitrile-based high-tensile carbon fiber textiles were heated by infrared emitters in an argon-rich atmosphere to temperatures between 450 and $1400{ }^{\circ} \mathrm{C}$. Single fiber tensile tests revealed a decrease in tensile strength and strain at fracture. Young's modulus was not affected. Scanning electron microscopy identified cavities on the fiber surface as the reason for the decrease in mechanical properties. They were caused by the attack of atmospheric oxygen. The atomic structure of the fibers did not change at any temperature, as $x$-ray diffraction confirmed. Based on these data, the pre-heating for the casting process can be optimized.
\end{abstract}

Keywords advanced characterization, aluminum, casting and solidification, composites, heat treatment, metallic matrix

\section{Introduction}

Carbon fiber textiles serve as reinforcement especially in polymer matrices and they are advancing at an accelerated rate. What is something of a rarity today will be affordable and widely used in the near future due to intensive efforts to realize cost-efficient automated production routes. Despite its extraordinary bending and tensile strength (Ref 1 ), carbon fiberreinforced polymers exhibit a lack of resistance against temperature and compressive stress. This deficit may be overcome by replacing the polymer matrix with a light metallike aluminum or magnesium (Ref 2-4). Local reinforcement of highly stressed regions in, e.g., engine parts, could be enabled.

In order to meet the demand for serial production of composites in the automotive and machine tool industry, a special high-pressure die casting process (HPDC) was developed (Ref 5-7). It features a short cycle time and also a short contact time between the molten aluminum alloy and the fibers. Due to the rapid solidification of the melt in the die, the main challenge is to properly infiltrate the fibrous preform. In the HPDC process, which we developed, the carbon fibers are heated by infrared lamps prior to casting to prevent premature

Franziska S. Kachold and Robert F. Singer, Chair of Metals Science and Technology, Friedrich-Alexander-Universität Erlangen-Nürnberg (FAU), Martensstr. 5, 91058 Erlangen, Germany; and Rafal Kozera and Anna Boczkowska, Faculty of Materials Science and Engineering, Warsaw University of Technology, ul. Woloska 141, 02-507 Warsaw, Poland. Contact e-mails: franziska.kachold@fau.de, rafal.kozera@inmat.pw.edu.pl, robert.singer@ww.uni-erlangen.de, and anna.boczkowska@inmat.pw.edu.pl. freezing of the melt. Carbon fibers exhibit very poor wettability by liquid aluminum alloys (Ref 8,9$)$ but a proper pre-heating process associated by high pressure can lead to almost complete infiltration of the fiber preform with aluminum. Without preheating, on the other hand over $40 \%$ of the fabric remain infiltrated (Ref 7). Other method for enhancement wettability is deposition of different coatings like, e.g., Ni-P (Ref 10-12). Non-coated carbon fibers start to oxidize when heated above $600{ }^{\circ} \mathrm{C}$ in air (Ref 13). This leads to a decay of the fiber's extraordinary mechanical properties, which also lowers the potential reinforcing effect.

Several authors, except changes in morphology (Ref 14, 15) describe a change in the properties of carbon fibers after different thermal treatments, i.e., removal of sizing in high vacuum, high pure air, or argon atmosphere (Ref 16-18) and also after the graphitization processes in the presence of metallic coatings (Ref 19, 20). But such laboratory conditions are often much different compared to industrial practice or at least conditions are fitted to actually utilized processing technologies, e.g., gas pressure infiltration. Therefore, the aim of the present work is to identify the effect of the carbon fibers textile pre-heating procedure carried out in industrial conditions using the innovative high-pressure die casting method which was not so far used for fabrication of MMC-reinforced by carbon fibers textiles. Pre-heating was realized by means of infrared lamps in a specific mix of argon and oxygen containing atmosphere. This allows for the determination of a temperature range in which both infiltration and mechanical properties are at a high level.

\section{Experimental}

A high-pressure die casting process was developed for the manufacturing of MMCs (Ref 7). The setup comprises short wave infrared emitters (Heraeus) just above the die (see Fig. 1) to pre-heat the fibers. A maximum power of $343 \mathrm{~kW} / \mathrm{m}^{2}$ allows 
for fast heating. The power of the lamps and the heating time are continuously adjustable. During the time of heating, argon gas is jetted toward the fibers to reduce the attack by oxygen. An automated linear guide unit moves the hot fibers inside the die where liquid aluminum shots in only 5 to $10 \mathrm{~s}$ after the heating lamps are turned off. For this study, the process was stopped after the pre-heating step and the fibers were not infiltrated with aluminum.

The used fabric was out of PAN-based high-tenacity carbon fibers of the type HTA40 from Toho Tenax. This fabric was made of fiber bundles with 24000, 12000, and 3000 filaments (Fig. 2b). Two layers of fabric were clamped into a steel frame. To measure the temperature during heating, three thermocouples (type K) were placed between the fabrics: one in the center of the plate and near the frame (Fig. 2a).

In this setup, the fabrics were heated to temperatures of 450 , $600,900,1200$, and $1400{ }^{\circ} \mathrm{C}$ as summarized in Table 1 . The temperature was recorded every $50 \mathrm{~ms}$ during heating and cooling.

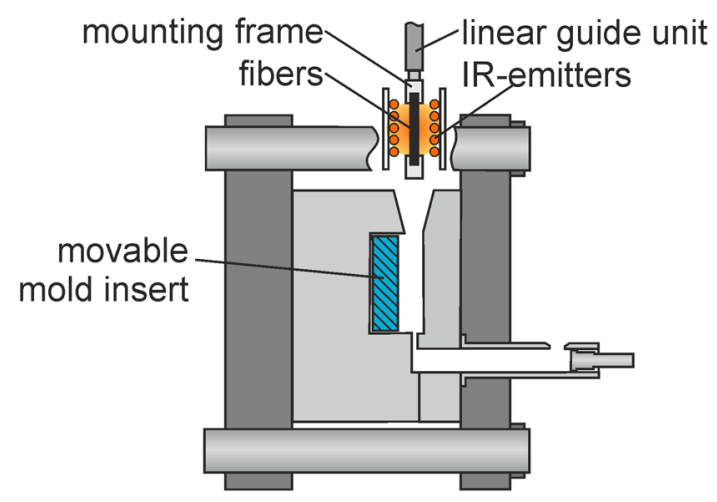

Fig. 1 Setup of high-pressure die casting process for the manufacturing of MMCs. The pre-heating system is placed above the die to keep time between heating and infiltration with melt short
To determine the tensile properties, 20 to 30 single fibers from each fabric were tested according to ASTM standard no. C1557-03 on a MTS Tytron 250 testing machine. The data were interpreted according to Weibull statistics, which is common for ceramic materials. The probability of fracture $P_{\mathrm{F}}$ in a brittle material is described by the fracture strength $\sigma_{\mathrm{F}}$, the characteristic strength $\sigma_{0}$, and the Weibull modulus $\mathrm{m}$ : $P_{\mathrm{F}}=1-\exp \left[-\left(\sigma_{\mathrm{F}} / \sigma_{0}\right)^{m}\right]$. To plot the data in a Weibull plot, the fracture probability was estimated by $P_{\mathrm{F}}=(i-0.5) / N$, where $N$ is the total number of samples which are arranged in ascending order with the rank $i$. The characteristic strength and the modulus were determined by the maximum-likelihood estimation. A detailed description of this method is given in the standard DIN EN 843-5.

The surface of the differently heated carbon fibers was studied using a high-resolution Hitachi S5500 SEM. Samples were stitched to the holder using carbon tape and investigated using $10 \mathrm{kV}$ accelerating voltage in SE mode. In addition, XRD patterns of an unheated sample and samples heated to 900 and $1200{ }^{\circ} \mathrm{C}$ were obtained using a Rigaku Miniflex II x-ray diffractometer equipped with a $\mathrm{Cu}$ cathode $(\lambda(\mathrm{Cu}-$ $\left.\mathrm{K}_{\alpha}\right)=1.54184 \AA$ ). The scan scope $(2 \theta)$ ranged from $20^{\circ}$ to $80^{\circ}$ at a scan rate of $4^{\circ} \cdot \mathrm{min}^{-1}$.

For all investigations, samples from the center of the fabric, where the maximum temperature was measured, were used.

\section{Table 1 Heating parameters of IR-lamps and resulting temperatures for the heating of carbon fibers}

\begin{tabular}{lcc}
\hline Temperature, ${ }^{\circ} \mathbf{C}$ & Power of IR-lamps, $\mathbf{k W} / \mathbf{m}^{\mathbf{2}}$ & Pre-heating time, $\mathbf{s}$ \\
\hline 450 & 35.9 & 20 \\
600 & 35.9 & 30 \\
900 & 59.9 & 20 \\
1200 & 343.2 & 20 \\
1400 & 343.2 & 30 \\
\hline
\end{tabular}

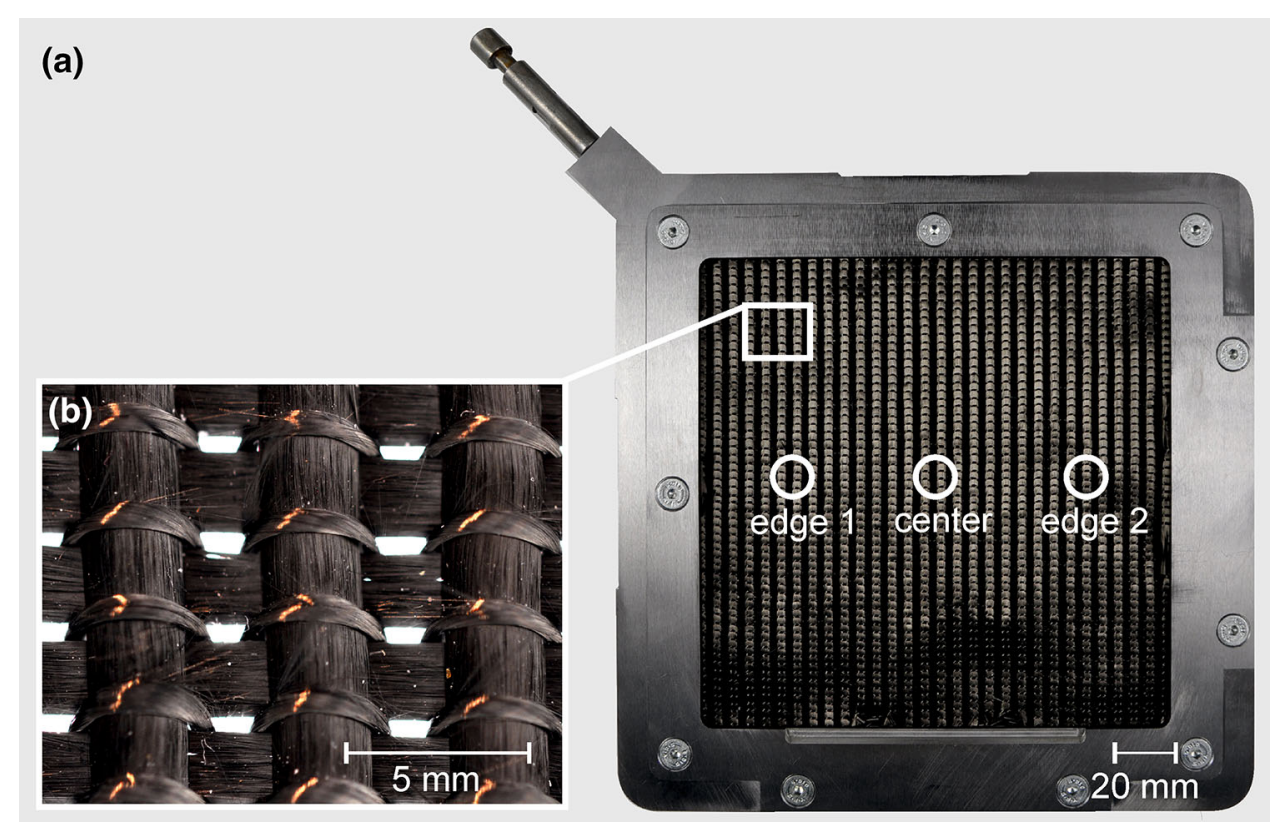

Fig. 2 Images of (a) carbon fiber fabric clamped into a steel frame, especially designed for HPDC. Positions of temperature measurement are marked by white circles; (b) single layer of carbon fiber fabric suitable for HPDC 


\section{Results}

\subsection{Heating}

The used IR-lamps heated carbon fibers rapidly. Figure 3 illustrates how a temperature of over $900{ }^{\circ} \mathrm{C}$ is reached in the center of the fabric after a heating time of $20 \mathrm{~s}$. The slow rise of the temperature in the beginning is due to the run-in period of the lamps and thermal conduction from the outside to the inside of the fiber body, where the thermo couples are placed. After this, the heating rate is almost constant. The temperature starts to decrease with a little delay from the time when the IRemitters are turned off. This delay is related to the afterglow of the lamps and the thermo couples' positions in the middle of the preform. Figure 3 also shows that the temperature in the center of the sample is around $200{ }^{\circ} \mathrm{C}$ higher than at the edges. The reason is the relatively cold steel frame, in which the fabrics are clamped. It is screened from radiation in order to avoid warpage. The conduction of thermal energy toward the frame creates a decrease of temperature from the center to the edge.

\subsection{Tensile Tests}

In tensile tests, the used carbon fibers behave purely elastic for all pre-heating temperatures. This is shown in exemplary stress-strain curves in Fig. 4. This is in agreement with the results from (Ref 21). Moreover, it can be seen that the slope of the curve, which corresponds to Young's modulus, remains

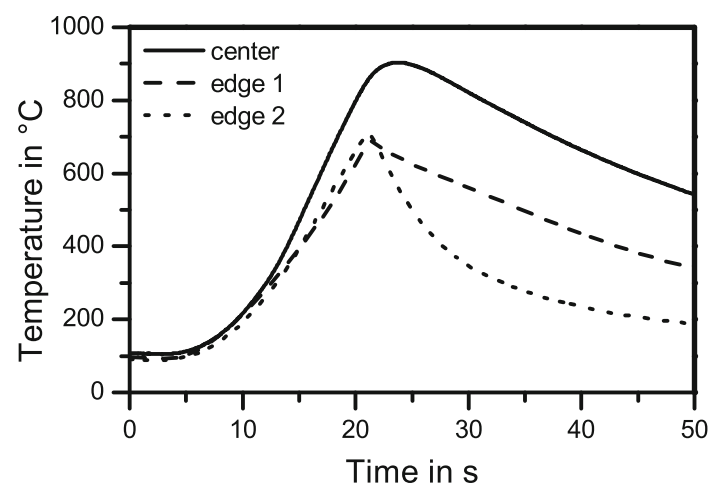

Fig. 3 Preform temperature as a function of time for the heating of carbon fibers via IR-lamps with a power of $59.9 \mathrm{~kW} / \mathrm{m}^{2}$ for $20 \mathrm{~s}$

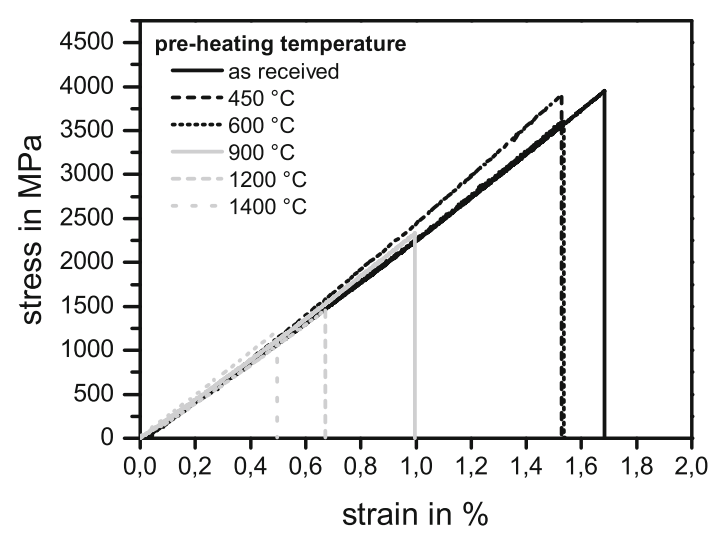

Fig. 4 Stress-strain curves of single carbon fibers heated to different temperatures approximately constant for all temperatures. The tensile strength, as well as the strain at fracture decreases with increasing temperature (Fig. 5).

A Weibull plot of the tensile strength of carbon fibers, which were pre-heated to different temperatures, is given in Fig. 6. The fracture probability of the experimentally determined data points was determined by a rank estimation function. The lines originate from the maximum-likelihood estimation.

Measurements on the original untreated fibers reveal a characteristic strength of $4100 \mathrm{MPa}$, which is very similar to the value of $3950 \mathrm{MPa}$ specified in the producer's data sheet. Slight differences in characteristic strength at $450{ }^{\circ} \mathrm{C}$ (4152 $\mathrm{MPa})$ and $600{ }^{\circ} \mathrm{C}(3953 \mathrm{MPa})$ can be attributed to statistical effects. This means there is no significant loss of tensile strength up to a temperature of $600{ }^{\circ} \mathrm{C}$. A further increase of temperature evokes a decline in characteristic strength. At $900{ }^{\circ} \mathrm{C}$, it decreased to $2707 \mathrm{MPa}$ which equals $66 \%$ of the original strength. For $1400{ }^{\circ} \mathrm{C}$, the highest temperature was investigated, the characteristic strength drops to $1082 \mathrm{MPa}$, retaining only $26 \%$ of the untreated fiber's strength.

For the Weibull modulus $\mathrm{m}$, which correlates to the scattering of the data, a value of around $m=5$ was found for fibers without pre-heating and with pre-heating to $600{ }^{\circ} \mathrm{C}$. At a temperature of $450{ }^{\circ} \mathrm{C}$, the modulus is increased to 10 . For higher temperatures, it is below 5. This increased scattering is due to varying defect sizes.

The strain at fracture displays a decrease at a comparable rate as the tensile strength. The original value of $1.7 \%$ is identical to the producer's specification and reduces significantly for pre-heating temperature over $600{ }^{\circ} \mathrm{C}$. For the temperature range between 900 and $1400{ }^{\circ} \mathrm{C}$, the strain at fracture averages between 59 and $29 \%$ of the value for the untreated fiber.

\subsection{Scanning Electron Microscopy}

SEM images of the fiber's surface before thermal treatments exhibit elongated grooves along the fiber axis, as displayed in Fig. 7(a). This is typical for PAN-based carbon fibers (Ref 22, 23) and originates from the production process.

The observation of the carbon fiber's surface after different pre-heating temperatures indicates significant changes in their

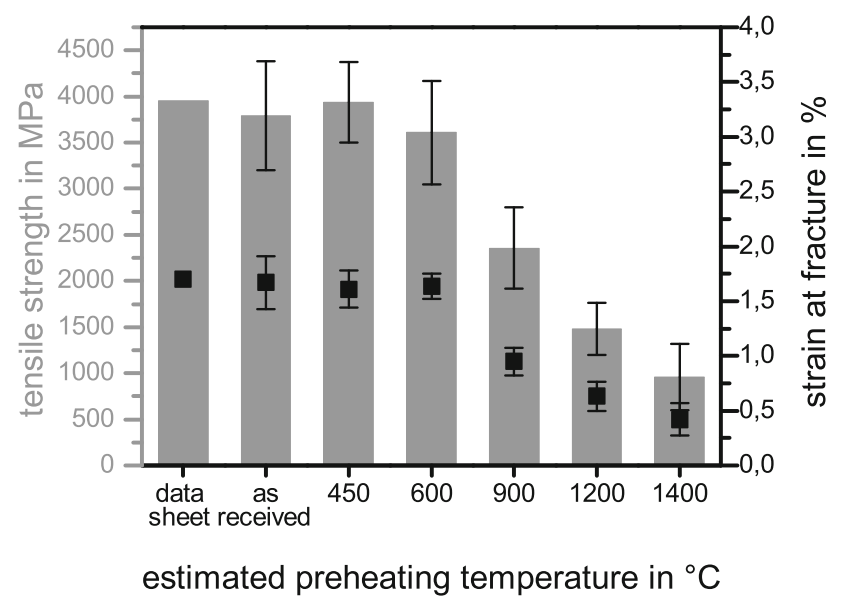

Fig. 5 Tensile strength measurements of the carbon fibers after different temperatures of pre-heating process 


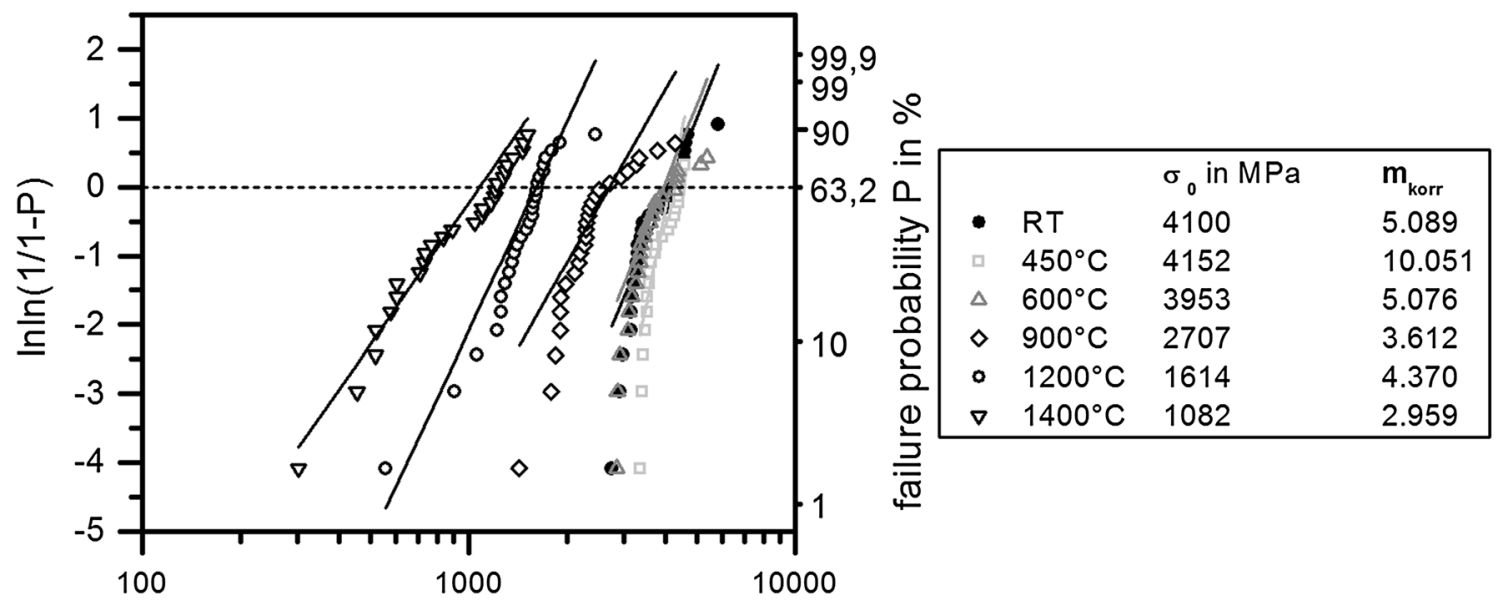

fracture strength in $\mathrm{MPa}$

Fig. 6 Weibull plot of failure probability as a function of fracture strength of carbon fibers, which were pre-heated at different temperatures. The characteristic strength decreases with increasing temperature

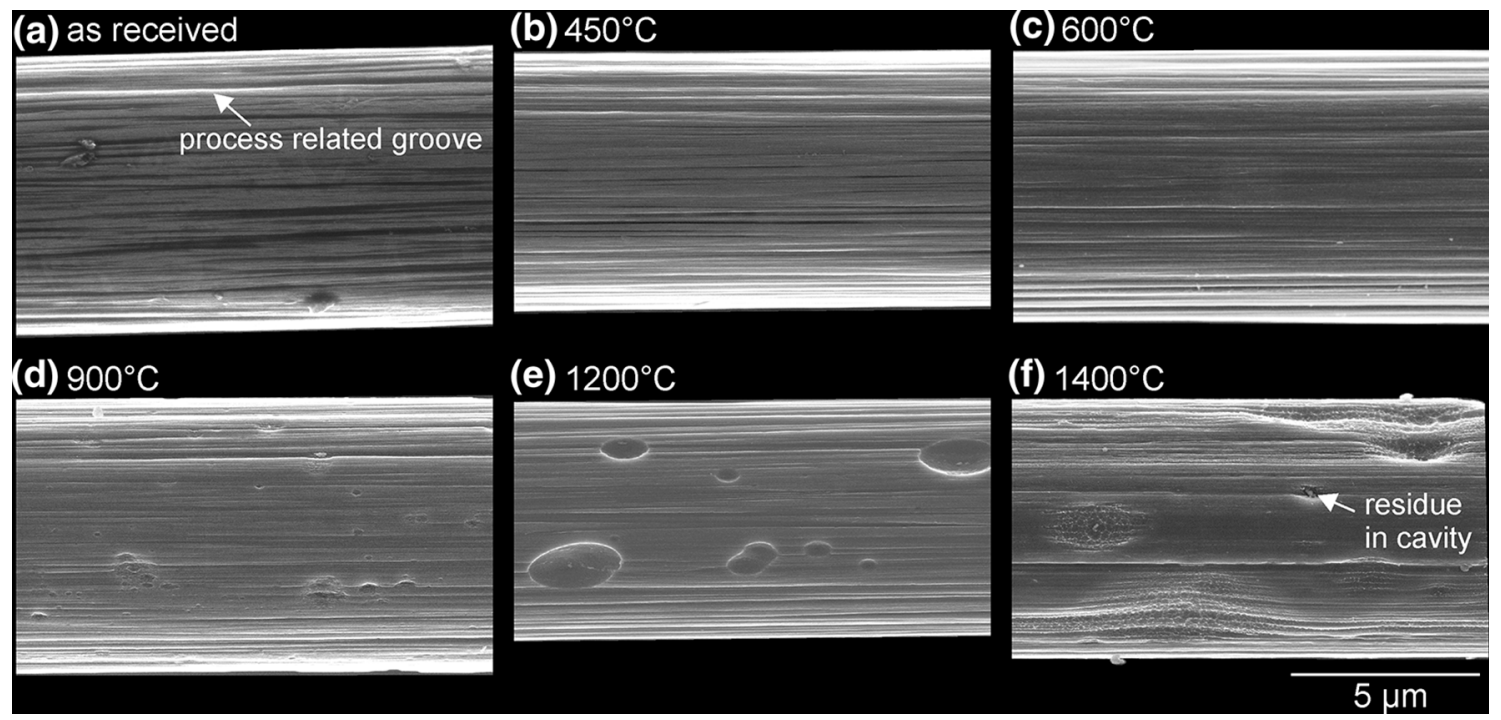

Fig. 7 SEM images of the surface of the carbon fibers as-received (a) and after pre-heating to $450{ }^{\circ} \mathrm{C}(\mathrm{b}), 600{ }^{\circ} \mathrm{C}(\mathrm{c}), 900{ }^{\circ} \mathrm{C}(\mathrm{d}), 1200{ }^{\circ} \mathrm{C}(\mathrm{e})$, $1400{ }^{\circ} \mathrm{C}$ (f). At $900{ }^{\circ} \mathrm{C}$ and above visible degradation occurs

morphology. Degradation increases with temperature. Figure 7(b) shows a fiber after pre-heating to $450{ }^{\circ} \mathrm{C}$. The morphology of the surface appears unchanged. Also at $600{ }^{\circ} \mathrm{C}$, no transformation in the surface morphology can be detected (Fig. 7c). A further increase of the temperature up to $900{ }^{\circ} \mathrm{C}$ causes degradation in the form of small cavities or grooves (Fig. 7d). At even higher temperatures, the grooves become more numerous and larger. At a temperature of $1200{ }^{\circ} \mathrm{C}$, the cavities reach a size of up to $2.5 \mu \mathrm{m}$ in diameter (Fig. 7e). In some cavities, small particles, potentially products of thermal degradation, were spotted. Reaching a pre-heating temperature of $1400{ }^{\circ} \mathrm{C}$, large cavities of irregular shape consume the original surface (Fig. 7f).

\section{$3.4 X R D$}

To detect possible changes in the atomic structure of heated carbon fibers, XRD was performed on unheated fibers and fibers heated to 900 and $1200{ }^{\circ} \mathrm{C}$. The diffraction pattern of untreated fibers displays a peak at an angle of $2 \theta=26^{\circ}$ (Fig. 8). This is a typical peak for carbon (Ref 24). The diffraction patterns of fibers heated up to 900 and $1200{ }^{\circ} \mathrm{C}$ feature a peak at the same position. The changes in the peak intensity are an effect of differing material volume. XRD results indicate that the atomic structure of carbon fibers is not affected by the pre-heating treatments. Graphitization of the fibers is unlikely to have occurred as no crystallization peak of carbon was found.

\section{Discussion}

Tensile testing clearly shows that the mechanical properties of high-tensile carbon fibers change with increasing temperature 


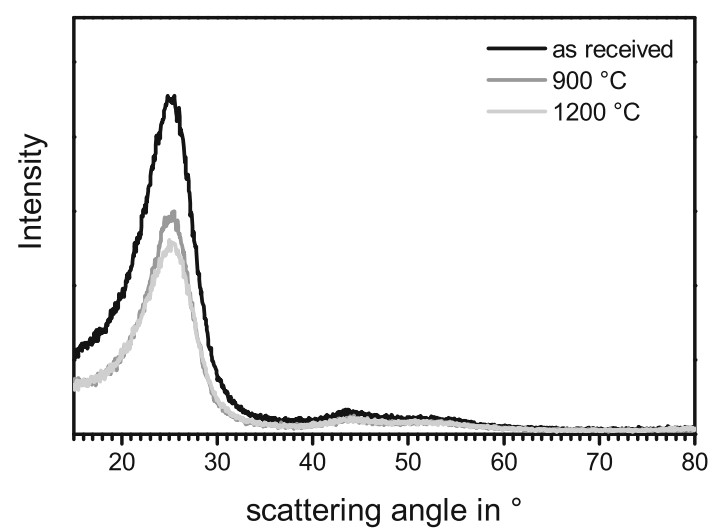

Fig. 8 X-ray diffraction patterns of the as-received carbon fibers and carbon fibers heated to 900 and $1200{ }^{\circ} \mathrm{C}$

of the pre-heating used in the described manufacturing process for MMCs. The decrease in tensile strength and strain at fracture is a result of the fibers' surface degradation, which was detected by SEM observations. It occurs due to the attack of oxygen. Even though the atmosphere is enriched with argon, it is not possible to completely avoid oxygen. This is in agreement with the results from (Ref 25). At temperatures above $600{ }^{\circ} \mathrm{C}$ and in the presence of oxygen, gaseous $\mathrm{CO}_{2}$ is produced ( $\operatorname{Ref} 8$ ), leaving holes in the surface of the fibers. These cavities act like notches and evoke stress concentrations which cause the tested fibers to fail much below their original strength. The particles found inside many cavities may be the residue of the oxidation process.

The oxidation process could be reduced, even for higher temperatures of up to $1100{ }^{\circ} \mathrm{C}$, by heating the fibers in an argon atmosphere of higher quality or in vacuum (Ref 16, 25-27). However, this is not practicable in HPDC.

A change in the atomic structure of the fibers as the reason for the decay of the mechanical properties at temperature over $600{ }^{\circ} \mathrm{C}$ can be excluded. No change in the atomic structure could be detected by the XRD measurements. Other authors (Ref 19) found that the graphitization process can start at $900{ }^{\circ} \mathrm{C}$. But the heating time of the fibers was much longer than in the present experiment.

These results indicate that the pre-heating temperature of the fabrics before infiltration in the high-pressure die casting process can be carried out in and over $600{ }^{\circ} \mathrm{C}$ but not exceed $900{ }^{\circ} \mathrm{C}$. The utilization of a higher temperature leads to the degradation of the fibers before they are infiltrated. Therefore, the great potential of carbon fibers to act as reinforcement in an MMC cannot be exploited to its full extent. However, in the MMC casting process, the fibers are not exposed to an oxygen containing atmosphere for such a long time. Just $5 \mathrm{~s}-10 \mathrm{~s}$ after the emitters are turned off, the melt infiltrates the fibers. Hence, the thermal damage of fibers in an actual MMC might be less.

\section{Conclusion}

The mechanical properties of high-tenacity carbon fibers are not affected by pre-heating to temperatures below $600{ }^{\circ} \mathrm{C}$ in an oxygen containing atmosphere. With higher temperatures, tensile strength and strain at fracture decrease more and more. At $1400{ }^{\circ} \mathrm{C}$, the fiber possesses only $24 \%$ of its original strength and $29 \%$ of its original strain at fracture. Through scanning electron microscopy, these changes were attributed to surface degradation due to oxygen attack. However, Young's modulus and the atomic structure of the fibers remain unchanged.

This knowledge is crucial to optimize the pre-heating process for the manufacturing of carbon fiber-reinforced aluminum by a novel high-pressure die casting because the pre-heating temperature should be kept between 600 and $900{ }^{\circ} \mathrm{C}$ to reach a degree of infiltration of over 95 vol.\%, while the excellent properties of CF are preserved. Thus, further studies should be performed to explore behavior of fibers during pre-heating process in the mentioned temperature range in order to find precise and optimized temperature for fibers processing.

\section{Acknowledgments}

The work is part of the Polish-German bilateral Project "3Dtextile reinforced Al-matrix composites (3DCF/Al-MMC) for complex stressed components in automobile applications and mechanical engineering" (PAK 258). We would like to thank the Polish Ministry of Science and Higher Education and the German Research Foundation for their financial support.

\section{Open Access}

This article is distributed under the terms of the Creative Commons Attribution 4.0 International License (http://creativecommons. org/licenses/by/4.0/), which permits unrestricted use, distribution, and reproduction in any medium, provided you give appropriate credit to the original author(s) and the source, provide a link to the Creative Commons license, and indicate if changes were made.

\section{References}

1. R.M. Jones, Mechanics of Composite Materials, CRC Press, London, 1998

2. S.K. Mazumdar, Composites Manufacturing Materials, Product and Process Engineering, CRC Press, London, 2002

3. C. Körner, W. Schäff, M. Ottmüller, and R.F. Singer, Carbon Long Fiber Reinforced Magnesium Alloys, Adv. Eng. Mater., 2000, 2(6), p 327-337

4. W. Schäff, M. Hagenbruch, C. Körner, R.F. Singer, Fabrication Process for Continuous Magnesium/Carbon-Fibre Composites with Graded Fibre Content. In: Proceedings of 5th International Symposium on Functionally Graded Materials, 1998

5. H. Eibisch, M. Hartmann, and R.F. Singer, Manufacturing and Properties of Continuous Carbon Fiber Reinforced Magnesium Produced by High Pressure Die Casting, Druckgusspraxis, 2004, 6, p 255-260 (in German)

6. H. Ballmes, A. Klassen, C.A. Rottmair, and R.F. Singer, Carbon Long Fiber Reinforced Aluminum Matrix Composites-Parameter Studies and Numerical Simulations of the Infiltration Process, Adv. Eng. Mater., 2010, 12, p 577-583

7. F.S. Kachold, H. Ballmes, R.F. Singer, Manufacturing of multidirectional carbon fiber aluminum composites by means of high presseure die casting. In: Proceedings of 19. Symposiums Verbundwerkstoffe und Werkstoffiverbunde, 2013, p 149-157 (in German)

8. D. Cho, B.I. Yoon, H.S. Ha, and Y.S. Lim, Microscopic Behavior on the Protection of Polyacrylonitrile-Based Carbon Fibers from Thermal Oxidation, Polym. J., 1997, 29(12), p 959-963

9. K. Landry, S. Kalogeropoulou, and N. Eustathopoulos, Wettability of Carbon by Aluminum and Aluminum Alloys, Mater. Sci. Eng. A, 1998, 254, p 99-111 
10. N. Eustathopoulos, M.G. Nicholas, and B. Drevet, Wettability at High Temperatures, Pergamon, Amsterdam, 1999

11. S. Ziyuan, W. Xuezhi, and D. Zhimin, The Study of Electroless Deposition of Nickel on Graphite Fibers, Appl. Surf. Sci., 1999, 140, p $106-110$

12. R. Kozera, J. Bieliński, A. Broda, A. Boczkowska, and K.J. Kurzydłowski, Preparation of Carbon Fibres for Aluminium Composites, Adv. Mater. Res., 2011, 264-265, p 1487-1493

13. J. Michalski, T. Wejrzanowski, S. Gierlotka, J. Bielinski, K. Konopka, T. Kosmac, and K.J. Kurzydlowski, The Preparation and Structural Characterization of $\mathrm{Al}_{2} \mathrm{O}_{3} / \mathrm{Ni}-\mathrm{P}$ Composites with an Interpenetrating Network, J. Eur. Ceram. Soc., 2007, 27(2-3), p 831-836

14. T. Wejrzanowski, M. Lewandowska, and K.J. Kurzydłowski, Stereology of Nanomaterials, Image Anal. Stereol., 2010, 29, p 1

15. R. Kozera, J.J. Bucki, A. Sałacinska, J. Bielinski, and A. Boczkowska, Quantitative Image Analysis of Ni-P Coatings Deposited on Carbon Fibers, J. Mater. Eng. Perform., 2015, 24(9), p 3400-3406

16. P.W. Jackson and J.R. Marjoram, Compatibility Studies of Carbon Fibres with Nickel and Cobalt, J. Mater. Sci., 1970, 5, p 9-23

17. E. Hajjar et al., The Effect of Applied Pressure on Fracture Surface and Tensile Properties of Nickel Coated Continuous Carbon Fiber Reinforced Aluminum Composites Fabricated by Squeeze Casting, Mater. Des., 2009, 31(5), p 2381-2386

18. P. Schulz, H. Kaufmann, and H. Capel, Mechanical Properties of Carbon Fibre-Reinforced $\mathrm{Al}$ and $\mathrm{Mg}$ Under Various Manufacturing Conditions, Microstructural Investigation and Analysis, B. Jouffrey, Ed., Wiley-VCH, Weinheim, 2000, p 128-132
19. H. Chi-Yuan, M. Wen-Wei, and R. Ming-Lih, The Influence of Heat Treatment on Electroless Nickel Coated Fibre (ENCF) on the Mechanical Properties and EMI, Shielding of ENCF Reinforced ABS Polymeric Composites, Surf. Coat. Technol., 2004, 184, p 123-132

20. P. Morgan, Carbon Fibers and Their Composites, CRC Press, London, 2005

21. A.J. Perry, E. Lamotte, and K. Phillips, The Tensile Properties of Nickel Coated Carbon Fibers, J. Mater. Sci., 1970, 5, p 945950

22. H.G. Seong, H.F. Lopez, D.P. Robertson, and P.K. Rohatgi, Interface Structure in Carbon and Graphite Fiber Reinforced 2014 Aluminum Alloy Processed with Active Fiber Cooling, Mater. Sci. Eng. A, 2008, 487, p 201-209

23. M.C. Paiva, C.A. Bernardo, and M. Nardin, Mechanical, Surface and Interfacial Characterization of Pitch and PAN-Based Carbon Fibers, Carbon, 2000, 38, p 1323-1337

24. J. Rams, A. Urena, M.D. Escalera, and M. Sanchez, Electroless Nickel Coated Short Carbon Fibres in Aluminium Matrix Composites, Compos. A, 2007, 38, p 566-575

25. R. Warren, C.H. Anderson, and M. Carlsson, High Temperature Compatibility of Carbon Fibres with Nickel, J. Mater. Sci., 1978, 13, p 178-188

26. R.B. Barclay and W. Bonfield, Carbon Fibre/Nickel Compatibility, J. Mater. Sci., 1971, 6(8), p 1076-1083

27. Y. Kimura, Y. Mishima, S. Umekawa, and T. Suzuki, Compatibility Between Carbon Fibre and Binary Aluminium Alloys, J. Mater. Sci, 1984, 19, p 3107-3114 